\title{
Regional variability in radiation-induced lung damage can be predicted by baseline CT numbers
}

Citation for published version (APA):

Defraene, G., van Elmpt, W., Crijns, W., \& De Ruysscher, D. (2017). Regional variability in radiationinduced lung damage can be predicted by baseline CT numbers. Radiotherapy and Oncology, 122(2), 300-306. https://doi.org/10.1016/j.radonc.2016.11.021

Document status and date:

Published: 01/02/2017

DOI:

10.1016/j.radonc.2016.11.021

Document Version:

Publisher's PDF, also known as Version of record

Document license:

Taverne

Please check the document version of this publication:

- A submitted manuscript is the version of the article upon submission and before peer-review. There can be important differences between the submitted version and the official published version of record.

People interested in the research are advised to contact the author for the final version of the publication, or visit the DOI to the publisher's website.

- The final author version and the galley proof are versions of the publication after peer review.

- The final published version features the final layout of the paper including the volume, issue and page numbers.

Link to publication

\footnotetext{
General rights rights.

- You may freely distribute the URL identifying the publication in the public portal. please follow below link for the End User Agreement:

www.umlib.nl/taverne-license

Take down policy

If you believe that this document breaches copyright please contact us at:

repository@maastrichtuniversity.nl

providing details and we will investigate your claim.
}

Copyright and moral rights for the publications made accessible in the public portal are retained by the authors and/or other copyright owners and it is a condition of accessing publications that users recognise and abide by the legal requirements associated with these

- Users may download and print one copy of any publication from the public portal for the purpose of private study or research.

- You may not further distribute the material or use it for any profit-making activity or commercial gain

If the publication is distributed under the terms of Article $25 \mathrm{fa}$ of the Dutch Copyright Act, indicated by the "Taverne" license above, 
Morbidity of lung cancer radiotherapy

\title{
Regional variability in radiation-induced lung damage can be predicted by baseline CT numbers
}

\author{
Gilles Defraene ${ }^{\mathrm{a}, \mathrm{b}, *}$, Wouter van Elmpt ${ }^{\mathrm{c}}$, Wouter Crijns ${ }^{\mathrm{d}}$, Dirk De Ruysscher ${ }^{\mathrm{a}, \mathrm{c}}$

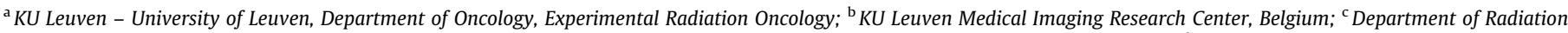

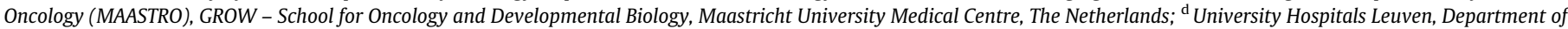 \\ Radiation Oncology, Belgium
}

\section{A R T I C L E I N F O}

\section{Article history:}

Received 6 July 2016

Received in revised form 24 October 2016

Accepted 26 November 2016

Available online 12 December 2016

\section{Keywords:}

Radiation-induced lung damage

Density change

CT

Regional heterogeneity

Lung cancer

Radiosensitivity

\begin{abstract}
A B S T R A C T
Background and purpose: Lung volumes are functionally heterogeneous but typically considered uniformly during radiotherapy planning. The present study aims to predict regional differences in radiation-induced lung damage based on pre-treatment $\mathrm{CT}$ information.

Materials and methods: For 42 lung cancer patients (including 15 from an external validation set), two $200 \mathrm{cc}$ lung subvolumes (low-density (LD) and high-density (HD)) were auto-segmented in the ipsilateral lung of the planning $\mathrm{CT}_{0}$. After non-rigid registration of 3 month follow-up $\mathrm{CT}$ scans, sigmoidal dosedensity change $\left(\Delta \mathrm{HU}=\mathrm{HU}_{3 \mathrm{M}}-\mathrm{HU}_{0}\right)$ response curves were determined for all subvolumes. Predictive factors for the sigmoidal response parameters $D_{50}$ and saturation level $\Delta H U_{\max }$ were analyzed.

Results: The baseline density difference between LD (mostly in the upper lobe) and HD (mostly in the lower lobe) was on average $102 \mathrm{HU}$. The saturation level $\Delta \mathrm{HU}_{\text {max,LD }}$ was significantly smaller than $\Delta \mathrm{HU}_{\max , \mathrm{HD}}(p=0.03)$. Expressed as mass density increase relative to the baseline density, saturation levels were $20.7 \%$ on average irrespective of baseline density, and they could be predicted in LD and HD subvolumes ( $A U C=0.70-0.78$ ). Intra-lung differences in $D_{50}$ were significantly smaller than interpatient differences.

Conclusions: Limited amount of damage was observed in LD subvolumes, while the relative density increase of all subvolumes was well predictable. This could allow dose redistribution preferentially targeting low-density lung regions.
\end{abstract}

(C) 2016 Elsevier Ireland Ltd. All rights reserved. Radiotherapy and Oncology 122 (2017) 300-306
Treatment dose prescription in (chemo)radiotherapy for stage III-IV non-small cell lung cancer is often limited by dose constraints applied on the normal lungs [1-3]. The resulting ad hoc lowered dose prescriptions often imply suboptimal tumor control probability. Widely accepted population-based dose constraints, limiting the incidence of significant radiation pneumonitis, are a mean lung dose (MLD) of both lungs below $20 \mathrm{~Gy}$ and a lung volume receiving $20 \mathrm{~Gy}\left(\mathrm{~V}_{20}\right)$ below $35 \%$ of the total lung volume [4-5]. Clinical risk factors for radiation pneumonitis development include age and smoking history [4-6].

A growing need for further lung toxicity risk-based individualization of the prescribed dose exists in the current era of modulated photon and particle treatments. In order to use these rapidly evolving treatment techniques to their full potential, better discriminating prediction models are required. This could partly be addressed by biomarkers of radiosensitivity [7]. While replicated

\footnotetext{
* Corresponding author at: KU Leuven - University of Leuven, Department of Oncology, Experimental Radiation Oncology, B-3000 Leuven, Belgium.

E-mail address: gilles.defraene@uzleuven.be (G. Defraene).
}

results applicable in routine clinical practice are not yet available from the field of radiogenomics, imaging biomarkers could provide useful information on shorter notice, including relevant spatial information [8].

Another approach for treatment individualization is to exploit regional heterogeneity in the lung. Indeed, the lung was considered a parallel organ with uniform characteristics in aforementioned work. However, it is known that lungs can be extremely heterogeneous in their structural composition as well as in their functional capacity [9]. Observed examples were the increased lung radiosensitivity of lower lobe tumor treatments [10-12] and nuclear imaging ventilation and perfusion scans unveiling dramatic differences in regional functionality [13].

The presence of radiation-induced lung damage is an important cause of clinical lung toxicity. Lung damage was quantified by the magnitude of density increase of lung parenchyma, or by other features derived from follow-up CT scans [14-19]. A large interpatient variability in dose response was observed for this lung damage endpoint $[8,18]$. Its correlation with clinical lung toxicity endpoints was shown in combination with the volume concerned 
by the damage [18,20,21]. Clearly, along the lines of exploiting regional lung characteristics, sparing lung regions at higher risk for damage while preferentially targeting low-risk regions could be a promising strategy.

A prediction model for patient-specific radiation-induced lung damage, based on characteristics of the baseline CT, was previously presented [18]. The median density of irradiated lung tissue, reflecting the density of the local lung structure, was shown to be correlated to the absolute amount of damage measured 3 months after treatment. Our hypothesis was that the same behavior exists on the level of subregions within the same lung, i.e. that the lowest density regions (portions of less dense lung parenchyma, emphysema, lung bullae, etc.) might remain unchanged after treatment, in contrast to high density regions at risk of pulmonary infiltrations. Identification of such regions at the planning stage could then guide dose deposition in order to minimize the risk of radiation-induced lung tissue damage.

The goal of present work was thus to investigate the translation of the inter-patient prediction model to subregions within the lung. Therefore, the damage of two lung subvolumes, differing in median baseline density, was quantified. Predictive factors for this lung heterogeneity were studied, as they could help in patient selection for lung damage risk-based dose redistribution planning.

\section{Materials and methods}

\section{Patient datasets}

A total of 42 stage III-IV lung cancer patients treated with intensity-modulated radiotherapy (IMRT) were retrieved from 2 institutions, further referred to as dataset 1 and 2 . The core of both datasets was an existing interinstitutional database described in detail in [18], from which all 30 IMRT treatments were selected.

Dataset 1 contained 27 patients from the University Hospitals Leuven (15 from previous work, enriched by 12 patients with a lower lobe tumor) treated up to $66 \mathrm{~Gy}$, in $2.75 \mathrm{~Gy}$ fractions sequentially with chemotherapy or in $2 \mathrm{~Gy}$ fractions concurrent with chemotherapy. 5- or 7-field IMRT or 2-arc RapidArc (RA) plans were delivered. The baseline planning $\mathrm{CT}\left(\mathrm{CT}_{0}\right)$ was a freebreathing CT and dose calculation of treatment plans was done with an Analytical Anisotropic Algorithm (AAA 10.0.28) from Eclipse (Varian Medical Systems, Palo Alto, CA).

Dataset 2 consisted of 15 patients treated at Maastro Clinic (all from previous work). Dose prescription was $45 \mathrm{~Gy}$ in $1.5 \mathrm{~Gy}$ fractions twice per day, followed by a boost up to $24 \mathrm{~Gy}$ ( $2 \mathrm{~Gy}$ fractions). $\mathrm{CT}_{0}$ was a $50 \%$ expiration 4DCT frame. IMRT plans calculated with a convolution superposition algorithm from XiO (Elekta, Stockholm, Sweden) were delivered.

Deep inspiration breath-hold diagnostic follow-up CT scans approximately 3 months after end of radiotherapy $\left(\mathrm{CT}_{3 \mathrm{M}}\right)$ were retrieved. All scans were taken in supine position with the arms raised above the head. Dyspnea scores (CTCAE 4.0) at the followup timepoint were retrospectively retrieved.

\section{Lung subvolume generation and damage analysis}

A predictive model for lung damage susceptibility on the patient level was previously designed. The model indicated that the median density calculated on $\mathrm{CT}_{0}$ within the $\mathrm{V}_{20}$ volume, was highly predictive for the observed lung density increase 3 months after treatment [18]. The effect was most pronounced in SABR treatments (with small $V_{20}$ volumes of on average $205 \mathrm{cc}$ ). This predictive factor was tested now for its ability to discriminate between damage susceptibility of different regions within the same lung. Two subvolumes of approximately $200 \mathrm{cc}$, named low-density (LD) and high-density (HD), were generated within the ipsilateral 'lung minus planning target volume (PTV)' using following user-independent strategy. The 'lung minus PTV' volume was sampled every $1.5 \mathrm{~cm}$ for voxels acting as seed points for region growing. The resulting region-growing volumes were expanded by a morphological closing operator. Only volumes were retained for which a dose-damage response analysis was possible at least from $20 \mathrm{~Gy}$ to $40 \mathrm{~Gy}$. From the remaining volumes, the two non-overlapping volumes with maximal difference in median baseline density $\left(\mathrm{HU}_{0}\right)$ were selected for the susceptibility study. All image analysis steps were performed in MeVisLab 2.6.2 (MeVis Fraunhofer, Bremen, Germany). More details on this subvolume autogeneration are described in Appendix 1.

For both the LD and HD subvolumes, a dose-damage response analysis was performed as previously reported [18]. In short, $\mathrm{CT}_{3 \mathrm{M}}$ was non-rigidly registered to $\mathrm{CT}_{0}$ using a free-form intensity-based registration algorithm of MIM 6.1.7 (MIM software, Cleveland, $\mathrm{OH}$ ). Subsequently, a difference image was created by voxelwise subtraction of $\mathrm{HU}$ values $\left(\Delta \mathrm{HU}=\mathrm{HU}_{3 \mathrm{M}}-\mathrm{HU}_{0}\right)$. From this difference image, the median HU value within $5 \mathrm{~Gy}$ dose bins (between $0 \mathrm{~Gy}$ and $60 \mathrm{~Gy}$ ) was calculated and plotted against the corresponding equivalent dose in $2 \mathrm{~Gy}$ fractions (EQD2, $\alpha / \beta=4 G y$, repopulation rate $=0.44 \mathrm{~Gy} /$ day ) [22,23]. Dose bins with a volume smaller than $1 \mathrm{cc}$ were not taken into account. The HU difference in the lowest dose bin was used as a reference (i.e. negligible damage at low dose was assumed).

Sigmoidal least squares fits of dose versus $\Delta H U$ data were produced for every lung subvolume, resulting in subvolume-specific damage parameters $\mathrm{D}_{50}$ and $\Delta \mathrm{HU}_{\max }$. Quality of the fit was expressed as the sum of squared residuals (SSR). The fit was qualified as acceptable when SSR $\leqslant 4000$, i.e. residuals being smaller than $20 \mathrm{HU}$ on average.

\section{Statistics}

Differences between the LD and HD damage parameters were analyzed with a paired $t$-test for continuous variables and a McNemar test for proportions, while all comparisons between both datasets relied on unpaired $t$-tests and Z-score, respectively $(0.05$ significance level). The average intra-patient difference in damage parameters was compared to the previously observed inter-patient distribution. A lognormal distribution was fitted to the interpatient data of Fig. 2b and d of [18]. Subsequently, for every patient, a datapoint pair was randomly generated from this interpatient distribution. Repeating this 1000 times resulted in a distribution of average inter-patient damage parameter difference for our sample size.

Both dataset 1 and 2 were combined to find predictors (univariate linear regression) for $\mathrm{HU}_{0}$ difference between $\mathrm{LD}$ and $\mathrm{HD}$, and for the damage parameters (using acceptable fits). Following covariates were analyzed: gender, age, PTV volume, ipsilateral 'lung minus PTV' volume, lung laterality, upper/middle or lower lobe tumor location, smoking status (current versus never/previous smoker), overall treatment time (OTT), MLD, mean and maximal heart dose $\left(D_{\text {mean }}, D_{\max }\right)$, and $\mathrm{CT}_{3 \mathrm{M}}$ timepoint. Damage parameters and grade $\geqslant 2$ dyspnea Spearman's correlation coefficients were calculated.

Finally, multivariate logistic regression models predicted the saturation level of relative mass density increase $\left(\Delta H U_{\max }\right)$ $\left.\left(1000+\mathrm{HU}_{0}\right)\right)$ above thresholds of $10 \%$ and $20 \%$. A forward selection procedure was performed on the combined dataset with the likelihood ratio test as comparison criterion (threshold $p=0.10$ ). Predictive accuracy of the models was assessed with stratified 3-fold cross-validation repeated 100 times. Median value and 95\% confidence interval (CI) of model performance on the unseen validation data were reported in terms of the area under the 
curve (AUC) of the receiver operating characteristic curve. Lastly, model coefficients optimized for dataset 1 were externally validated in dataset 2 .

\section{Results}

Patient and treatment characteristics are listed in Table 1. Optimal lung subvolumes with an average size of $187.6 \mathrm{cc}$ and $216.5 \mathrm{cc}$ were generated in both datasets. LD and HD subvolumes had median $\mathrm{HU}_{0}$ values of on average $-834 \mathrm{HU}$ and $-725 \mathrm{HU}$ in dataset 1 and $-853 \mathrm{HU}$ and $-763 \mathrm{HU}$ in dataset 2 , respectively. Average value and range of $\mathrm{HU}_{0}$ difference between $\mathrm{LD}$ and $\mathrm{HD}$ was $109 \mathrm{HU}$ ( $45 \mathrm{HU} ; 196 \mathrm{HU}$ ) and $90 \mathrm{HU}(23 \mathrm{HU} ; 213 \mathrm{HU}$ ) in both datasets, respectively. LD subvolumes were situated completely in the upper lobe in 30 out of 42 patients, and completely in the lower lobe in only 4 patients. HD subvolumes' location was completely in the lower lobe in 21 patients, and in the upper lobe in 6 patients. Characteristics of the optimal subvolumes are described in Table 2. Fig. 1 displays a patient example with optimized subvolumes and corresponding damage response curves.

Dose-damage response analysis resulted in average values of $\Delta \mathrm{HU}_{\max , \mathrm{LD}}=30 \mathrm{HU}$ and $\Delta \mathrm{HU}_{\max , \mathrm{HD}}=47 \mathrm{HU}$, combining both data- sets $(p=0.027)$. This difference was more pronounced in dataset $2(p=0.0022)$. For 32 out of 42 patients (and 22/26 patients with acceptable fits) $\Delta \mathrm{HU}_{\mathrm{max}, \mathrm{HD}}$ was equal or larger than $\Delta \mathrm{HU}_{\mathrm{max}, \mathrm{LD}}$. For 21/32 patients (and 13/22 with acceptable fits) this difference was larger than $20 \mathrm{HU}$. Fig. 2 depicts the dependence of $\Delta \mathrm{HU}_{\max }$ on $\mathrm{HU}_{0}\left(R^{2}=0.09\right)$, however, a large spread on the data was present. The best linear fit to all datapoints as depicted in Fig. 2, corresponded to an almost constant relative mass density increase, irrespective of $\mathrm{HU}_{0}$. No significant difference was observed between $\mathrm{D}_{50, \mathrm{LD}}$ and $\mathrm{D}_{50, \mathrm{HD}}(p=0.69)$. The absolute difference between $\mathrm{D}_{50}$, LD and $\mathrm{D}_{50, \mathrm{HD}}$ was $15.1 \mathrm{~Gy}$ on average (only $12.0 \mathrm{~Gy}$ in dataset 2). Randomly simulated inter-patient pairs of $\mathrm{D}_{50}$ showed higher differences in $87.1 \%$ of cases. For dataset 2 this was $99.2 \%$ (95\% CI : 94.6-100.0\%).

Male gender and higher MLD were significantly associated with higher $\mathrm{HU}_{0}$ difference between $\mathrm{LD}$ and $\mathrm{HD}$ in univariate analysis ( $p=0.036$ and $p=0.030$ respectively). As for the damage parameters, associations of lower age $(p=0.038)$ with $\Delta H U_{\text {max,LD }}$ and heart $\mathrm{D}_{\max }(p=0.011)$ with $\Delta \mathrm{HU}_{\max , \mathrm{HD}}$ were present. A higher $\mathrm{HU}_{0, \mathrm{HD}}$ was a univariate predictor for $\Delta \mathrm{HU}_{\mathrm{max}, \mathrm{HD}}$ in dataset $2(p=0.016)$. No significant correlations with dyspnea scores were observed $(p>0.20)$.

Table 1

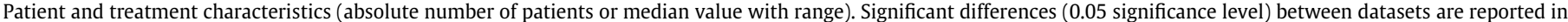
the fourth column (Z-score for proportions, unpaired $t$-test for continuous variables).

\begin{tabular}{|c|c|c|c|}
\hline & Dataset $1(n=27)$ & Dataset $2(n=15)$ & Dataset 1 vs Dataset 2 \\
\hline \multicolumn{4}{|l|}{ Gender } \\
\hline Male & 16 & 7 & 1 \\
\hline Female & 11 & 8 & 1 \\
\hline Age & $64.6(17.0 ; 82.8)$ & $68.4(51.8 ; 82.1)$ & 1 \\
\hline \multicolumn{4}{|l|}{ Tumor location } \\
\hline Left upper/middle lobe & 7 & 2 & 1 \\
\hline Right upper/middle lobe & 4 & 6 & 1 \\
\hline Left lower lobe & 3 & 2 & 1 \\
\hline Right lower lobe & 12 & 2 & 0.040 \\
\hline Combined location & 1 & 3 & 1 \\
\hline \multicolumn{4}{|l|}{ Chemotherapy regimen } \\
\hline None & 7 & 0 & 0.031 \\
\hline Sequential & 2 & 1 & 1 \\
\hline Concurrent & 18 & 9 & 1 \\
\hline Concurrent + cetuximab & 0 & 5 & 0.0014 \\
\hline \multicolumn{4}{|l|}{ Smoking status } \\
\hline Never & 1 & 1 & 1 \\
\hline Ex-smoker & 20 & 11 & 1 \\
\hline Current smoker & 6 & 1 & 1 \\
\hline Unknown & 0 & 2 & 1 \\
\hline FEV1(l) & $2.10(0.92 ; 3.07)$ & $\mathrm{N} / \mathrm{A}$ & $\mathrm{N} / \mathrm{A}$ \\
\hline \multicolumn{4}{|l|}{ Treatment technique } \\
\hline IMRT & 20 & 15 & 0.031 \\
\hline RapidArc & 7 & 0 & 0.031 \\
\hline PTV volume (cc) & $552.2(87.8 ; 1466.3)$ & 309.7 (72.5; 996.1) & 0.034 \\
\hline Ipsilateral lung-PTV volume on $C T_{0}(c c)$ & $1468(444 ; 2438)$ & $1832(1016 ; 3267)$ & 0.0014 \\
\hline$C T_{3 M}$ time (months after end of $R T$ ) & $2.6(0.9 ; 4.3)$ & $2.8(1.4 ; 4.1)$ & 1 \\
\hline Mean Lung Dose (Gy physical dose) & $18.7(7.6 ; 22.6)$ & $13.0(6.5 ; 19.8)$ & 0.0006 \\
\hline \multicolumn{4}{|l|}{ Heart dose (Gy physical dose) } \\
\hline$D_{\max }$ & $65.7(40.3 ; 71.8)$ & $57.0(0.5 ; 71.4)$ & 0.0033 \\
\hline$D_{\text {mean }}$ & $16.9(3.5 ; 28.3)$ & $7.5(0.1 ; 18.1)$ & 0.0001 \\
\hline Overall treatment time (days) & $44(23 ; 49)$ & $36(25 ; 39)$ & 0.0075 \\
\hline \multicolumn{4}{|l|}{ Dyspnea score at follow-up } \\
\hline Grade 0 & 4 & 8 & 0.0081 \\
\hline Grade 1 & 9 & 5 & 1 \\
\hline Grade 2 & 8 & 2 & 1 \\
\hline Grade 3 & 4 & 0 & 1 \\
\hline Unknown & 2 & 0 & 1 \\
\hline
\end{tabular}

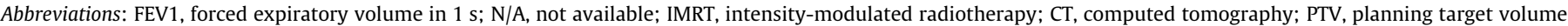
lung-PTV, lung minus PTV. 
Table 2

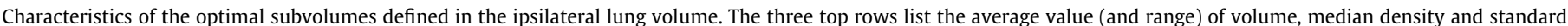

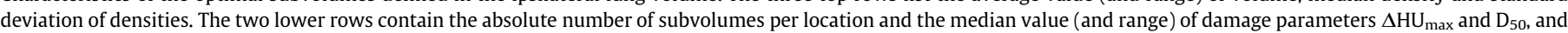

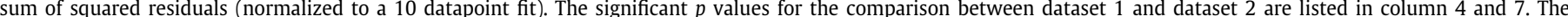

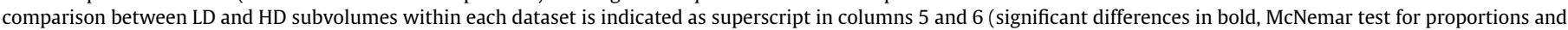
paired $t$-test for continuous variables).

\begin{tabular}{|c|c|c|c|c|c|c|}
\hline & \multicolumn{3}{|c|}{ Low-density (LD) subvolume } & \multicolumn{3}{|c|}{ High-density (HD) subvolume } \\
\hline & Dataset $1(n=27)$ & Dataset $2(n=15)$ & Dataset 1 vs Dataset 2 & Dataset $1(n=27)$ & Dataset $2(n=15)$ & Dataset 1 vs Dataset 2 \\
\hline Volume (cc) & $\begin{array}{l}195.0 \\
(53.0 ; 298.5)\end{array}$ & $\begin{array}{l}216.0 \\
(112.1 ; 423.3)\end{array}$ & 1 & $\begin{array}{l}180.2 \\
(65.8 ; 314.0)\end{array}$ & $\begin{array}{l}217.1 \\
(127.6 ; 390.3)\end{array}$ & I \\
\hline Median baseline density (HU) & $\begin{array}{l}-834 \\
(-912 ;-769)\end{array}$ & $\begin{array}{l}-853 \\
(-927 ;-802)\end{array}$ & 1 & $\begin{array}{l}-725^{p<0.001} \\
(-641 ;-806)\end{array}$ & $\begin{array}{l}-763^{p<0.001} \\
(-641 ;-861)\end{array}$ & $p=0.022$ \\
\hline SD baseline density $(H U)$ & $\begin{array}{l}105.6 \\
(79.5 ; 145.9)\end{array}$ & $\begin{array}{l}\mathbf{1 1 2 . 9} \\
(79.1 ; 148.3)\end{array}$ & 1 & $\begin{array}{l}\text { 141.9 } \\
(87.3 ; 190.8)\end{array}$ & $\begin{array}{l}\mathbf{1 7 0 . 2}^{\boldsymbol{p}<0.001} \\
(105.9 ; 254.6)\end{array}$ & $p=0.0068$ \\
\hline \multicolumn{7}{|l|}{ Location } \\
\hline Upper/middle lobe & 21 & 9 & 1 & $4^{p=0.0014}$ & 2 & I \\
\hline Lower lobe & 3 & 1 & 1 & $15^{p=0.0095}$ & 6 & I \\
\hline Combined & 3 & 5 & 1 & 8 & 7 & I \\
\hline \multicolumn{7}{|l|}{ Damage parameter } \\
\hline$\Delta \mathrm{HU}_{\max }(\mathrm{HU})$ & $\begin{array}{l}23.6 \\
(0.0 ; 150.0)\end{array}$ & $\begin{array}{l}13.7 \\
(0.0 ; 51.5)\end{array}$ & 1 & $\begin{array}{l}45.6 \\
(0.0 ; 150.0)\end{array}$ & $\begin{array}{l}\mathbf{4 3 . 4}^{\mathbf{p = 0 . 0 0 2}} \\
(0.0 ; 84.7)\end{array}$ & I \\
\hline $\mathrm{D}_{50}(\mathrm{~Gy})$ & $\begin{array}{l}31.1 \\
(15.6 ; 57.0)\end{array}$ & $\begin{array}{l}22.8 \\
(10.0 ; 60.0)\end{array}$ & 1 & $\begin{array}{l}30.1 \\
(10.0 ; 60.0)\end{array}$ & $\begin{array}{l}29.4 \\
(14.4 ; 60.0)\end{array}$ & I \\
\hline Sigmoidal fit SSR & $\begin{array}{l}330.4 \\
(64.9 ; 8123.5)\end{array}$ & $\begin{array}{l}852.8 \\
(76.8 ; 9575.8)\end{array}$ & 1 & $\begin{array}{l}\mathbf{2 7 3 1 . 9}^{\mathbf{p}=\mathbf{0 . 0 0 7}} \\
(56.5 ; 24680.0)\end{array}$ & $\begin{array}{l}1146.7 \\
(229.2 ; 12238.9)\end{array}$ & 1 \\
\hline
\end{tabular}

Abbreviations: $n$, number of patients; HU, Hounsfield units; SD, standard deviation; SSR, sum of squared residuals.
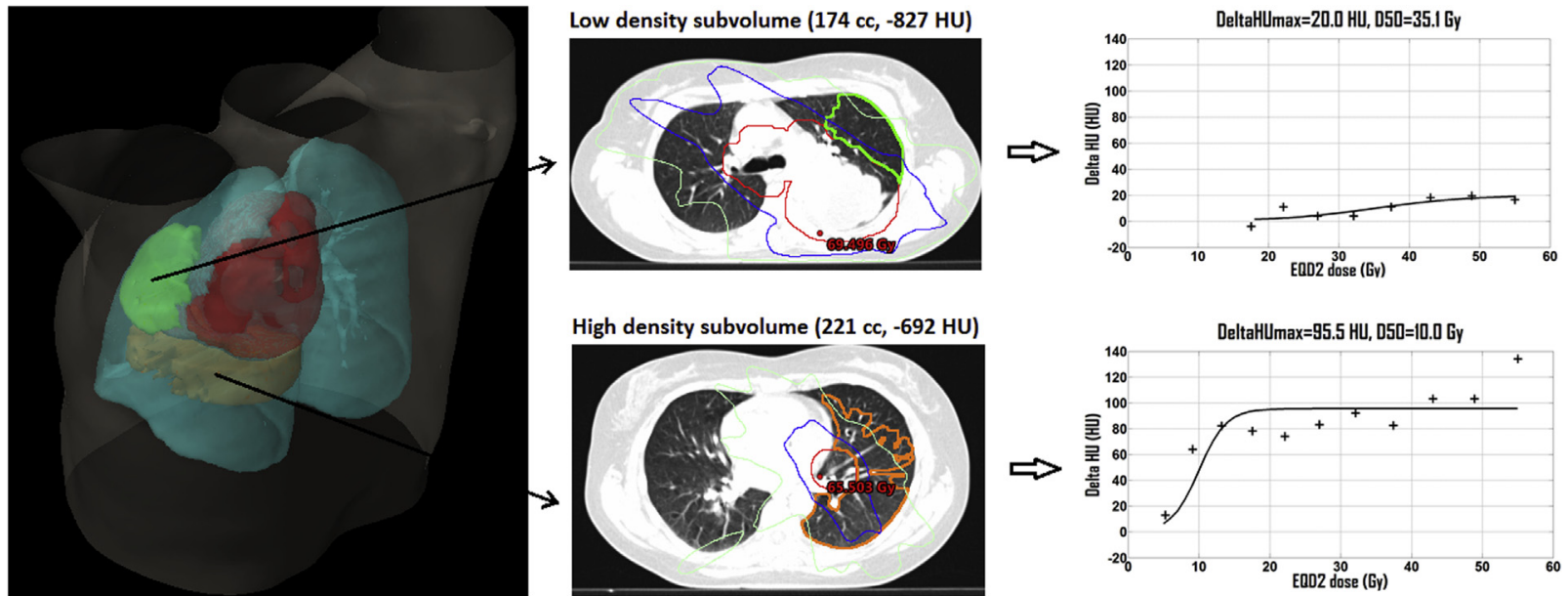

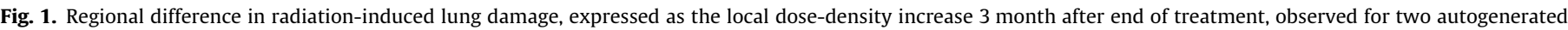

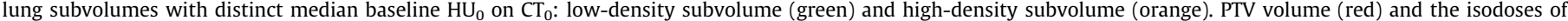
$40 \mathrm{~Gy}$ (blue) and $20 \mathrm{~Gy}$ (green) are shown on the axial CT slices.

Predictive models of relative mass density increase (Table 3 ) were based in HD subvolumes on the covariates laterality and OTT (AUC of 0.78 (95\% CI: 0.43-0.95)), and in LD subvolumes on the covariates age and $\mathrm{CT}_{3 \mathrm{M}}$ timepoint (AUC between $0.70(95 \%$ CI: $0.40-0.95)$ and 0.72 (95\% CI: 0.39-0.94)). Only the HD model showed moderate performance in the external validation set (AUC $=0.63$ ), with the AUC of LD models below 0.5.

\section{Discussion}

This work is to our best knowledge the first to observe and predict distinct radiation-induced lung damage assessed on CT between selected lung subvolumes. In a database of 42 intensitymodulated radiotherapy treatments for lung cancer, more than $100 \mathrm{HU}$ difference was obtained between $200 \mathrm{cc}$ lung subvolumes in $40 \%$ of patients. The use of a user-independent region growing-based algorithm for subvolume definition resulted in optimal subvolumes which were similar to an expert's manual delineation. Verification in a subgroup of 12 patients led to similar locations and damage analyses, especially for LD subvolumes (data not shown). The LD location was mostly in the upper lobe, even for lower lobe tumor treatments, as lymph node irradiation implied significant doses throughout both lung lobes in most patients. Hence also the observed correlation of MLD with the obtained $\mathrm{HU}_{0}$ difference.

Sigmoidal dose-density increase response curves described by two parameters were analyzed as a surrogate lung tissue damage endpoint 3 month after end of treatment. The dosimetric damage parameter $D_{50}$ was patient-specific rather than subvolumespecific, as indicated by the small average difference between $D_{50, L D}$ and $D_{50, H D}$. No predictor was found for $D_{50}$ in any of the subvolumes or datasets. This supports our hypothesis that it is a measure of patient individual intrinsic radiosensitivity of lung tissue. Future radiogenomics studies investigating a genetic basis for this 


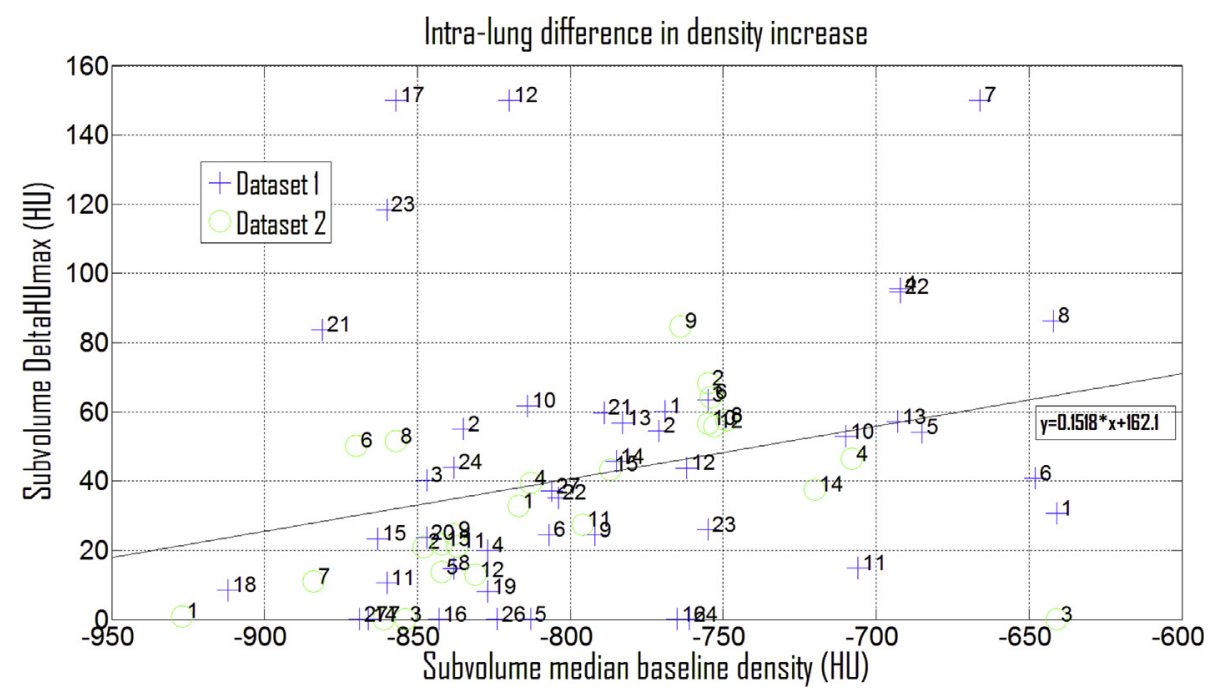

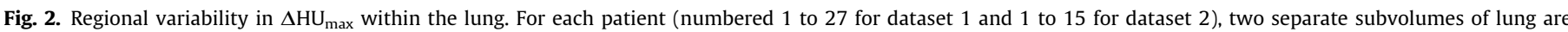

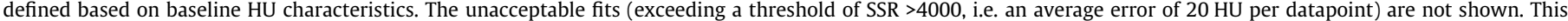

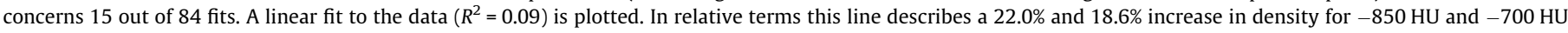
baseline density subvolumes, respectively.

Table 3

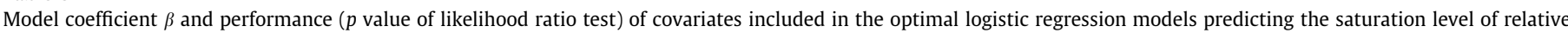

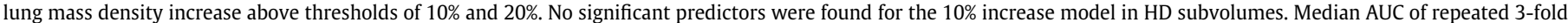
cross-validation is reported.

\begin{tabular}{|c|c|c|c|c|}
\hline \multirow[t]{2}{*}{ HD subvolume } & \multicolumn{2}{|c|}{$10 \%$ increase (NA) } & \multicolumn{2}{|c|}{$20 \%$ increase $(\mathbf{A U C}=\mathbf{0 . 7 8})$} \\
\hline & $\beta$ & $p$ & $\beta$ & $p$ \\
\hline Laterality: right lung & 1 & 1 & 0.957 & 0.030 \\
\hline OTT (days) & 1 & 1 & -0.136 & 0.077 \\
\hline \multirow[t]{2}{*}{ LD subvolume } & \multicolumn{2}{|c|}{$10 \%$ increase $(\mathbf{A U C}=\mathbf{0 . 7 2})$} & \multicolumn{2}{|c|}{$20 \%$ increase $(\mathbf{A U C}=\mathbf{0 . 7 0})$} \\
\hline & $\beta$ & $p$ & $\beta$ & $p$ \\
\hline Age (years) & -0.071 & 0.058 & -0.081 & 0.073 \\
\hline $\mathrm{CT}_{3 \mathrm{M}}$ timepoint (months) & 1 & 1 & 1.709 & 0.023 \\
\hline
\end{tabular}

Abbreviations: HD, high-density; LD, low-density; AUC, area under the curve; OTT, overall treatment time.

individual radiosensitivity could thus benefit from this knowledge $[8,18]$. The significant difference in observed saturation level $\Delta \mathrm{HU}_{\max }$ between LD and HD subvolumes could partly be explained by LD and HD baseline density itself, which reflects the initial lung structure. It should be noted that mathematically two dose-density increase sigmoids with identical $D_{50}$ and slope $\gamma$ (which remained unchanged in the fits), but different $\Delta H U_{\max }$ by a factor $d$, describe a difference in density increase by a factor $d$ at every dose level. This heterogeneity in amount of damage could thus be exploited in treatment planning using low-density regions, e.g. bullae, which remain essentially unchanged with high probability, as window for dose deposition, i.e. a dose redistribution planning. For HD subvolumes the relative increase in mass density could be predicted with moderate to high AUC by OTT and tumor laterality, which implies it is less appropriate as intrinsic radiosensitivity measure. Finally, it should be stressed that the findings do not imply a difference in intra-patient radiosensitivity between lung tissue at different densities. Indeed, an average $20.7 \%$ mass density increase was observed throughout all subvolumes.

Several efforts to identify functional (ventilation/perfusion) heterogeneity within the lungs and to exploit this in dose redistribution plans have been performed [24-27]. The first experience of functional avoidance radiotherapy based on these principles was recently published [28]. However, dose volume histogram (DVH) parameters of the high-perfusion lung region were shown to only slightly improve the correlation with clinical toxicity endpoints in another study [29]. Reducing lung damage on a large volume of susceptible lung by dose redistribution according to our work, could possibly have more clinical impact. An advantage of CT number-based dose redistribution is indeed that the targeted low-density regions as emphysema cannot recover after treatment, while using functional imaging, temporarily unventilated/unperfused parts, e.g. due to airways blocked by the tumor, could potentially recover but are targeted instead. High-density regions of lung are likely to be functionally important [30]. In whole-lung densitometry, metrics as the 15 th percentile of density were described as a robust surrogate for emphysema extent [31]. Cigarette smokeinduced emphysema is mostly located in the upper lobe, partly by regional molecular heterogeneity [32]. While, in our work, most LD subvolumes were found in the upper lobe, no correlation was found between subvolumes' $\mathrm{HU}_{0}$ difference and smoking status.

Lower lobe treatments were associated with more fibrosis and clinical expression of toxicity [10-12]. We therefore selected an equal number of treatments for lower and upper lobe tumors. The HD subregions, indicating a dense lung structure, were located predominantly in the lower lobe. However, lower lobe tumor location was not found to significantly predict for density increase parameters. Other predictors of lung tissue density increase after radiotherapy as higher age [33] and heart irradiation [34] were reported, while cardiac comorbidity was shown to be an indepen- 

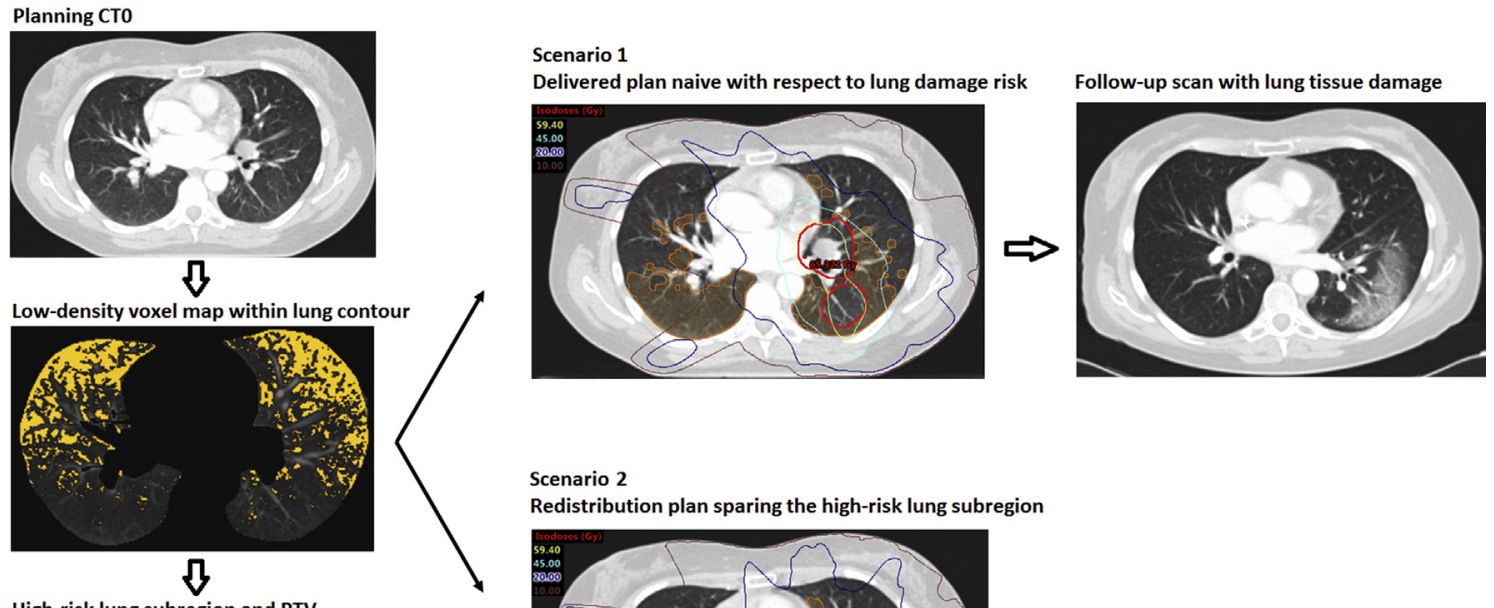

Scenario 2

Redistribution plan sparing the high-risk lung subregion
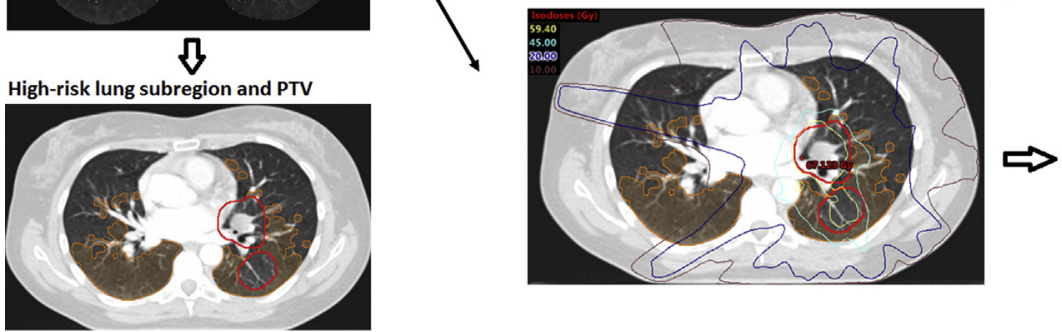

Follow-up scan at lower risk for

lung tissue damage?

Fig. 3. Redistribution planning concept based on the findings of increased lung damage risk in high-density lung subregions, same patient as in Fig. 1 (number 4 of dataset 1 ). A planning $\mathrm{CT}_{0}$ slice through the caudal part of PTV is visualized on the upper left figure. In a first step shown below, low-density voxels below -800 HU (low damage risk) within the 'lungs minus GTV' contour were defined (orange overlay). Next, applying morphological opening and closing operators resulted in a low-risk volume. On the lower left, the remaining high-risk lung structure (orange) lying outside of PTV (red) was transferred to the TPS. The second column shows the delivered IMRT plan naïve with respect to lung damage risk. The ipsilateral high-risk region was completely covered by the $45 \mathrm{~Gy}$ isodose. Corresponding CT slice of follow-up scan 2,5 month after end of treatment (upper right figure) contained a damaged lung subregion overlapping with high-risk and PTV volumes (rigid registration with $\mathrm{CT}_{0}$ ). The lower part of second column shows the dose redistribution plan with additional constraints on the high-risk subregion resulting in a local shift of the 45 Gy isodose for similar PTV and OAR DVH metrics.

dent risk factor for post RT dyspnea [35]. In our datasets, lower age was a risk factor for LD density increase, which possibly reflects the lower prevalence of bullae in younger patients. Heart $\mathrm{D}_{\max }$ significantly predicted for $\Delta \mathrm{HU}_{\mathrm{max}, \mathrm{HD} \text {. }}$

A first limitation of the study was the different baseline CT frame used in both datasets. The breathing state possibly influenced subvolume size (smaller in free-breathing scans) and the lower subvolume densities in dataset 2 . The lower quality of dose-damage fits compared to the fits in [18] could be explained by the limited planned dose accuracy and the challenging nonrigid registration, resulting in significant uncertainties when analyzing dose bins as small as $1 \mathrm{cc}$. LD and HD damage parameter results being more conclusive in dataset 2 (better motion management protocol) supported this.

Secondly, the limited size of the datasets should be kept in mind for covariates as smoking status (few current smokers). This could have lead to overfitting in some of the logistic regression models built during repeated $\mathrm{CV}$, as indicated by the broad $95 \% \mathrm{CI}$ of observed AUC. Also, the follow-up time was not exactly 3 months in these retrospective datasets. Time was therefore included as covariate in the analyses, as it is known to affect damage visible on CT scans [16-18,36]. Longer follow-up time was confirmed as a predictive factor for the LD 20\% density increase risk.

Third, fibrosis in the lung might have been captured as healthy densely structured lung, which could explain some outliers at high $\mathrm{HU}_{0}$ in Fig. 2. Focusing primarily on the low-density regions in a dose redistribution setting could circumvent this issue. Few large bullae were seen in our datasets, certainly not of the extent of $200 \mathrm{cc}$. This could be more pronounced in lungs of SABR treatments. However, the possible damage reduction by a dose redistribution concept is not likely to be clinically relevant for the small SABR isodoses. The recently published positive effect of having $1854 \mathrm{cc}$ spared from $40 \mathrm{~Gy}$ illustrates this [37]. The presented models were built for modulated treatments, as these are required to sculpt doses in redistribution planning.

A planning study is currently being performed to define the minimal size of LD subvolumes that can reliably influence delivered dose maps. A $\mathrm{HU}_{0}$ threshold could be chosen based on Fig. 2 for the generation of LD volumes, dependent on the accepted risk of damage for an individual patient. Based on the total volume of LD segmentations, and the remaining HD volume, the prediction model for HD relative density increase could be used. A more efficient volume selection will be possible as we were bound to restrictions on overlap with $<20 \mathrm{~Gy}$ and $>40 \mathrm{~Gy}$ regions. The obtained subvolumes could then be incorporated into the objective function of inverse optimization in state-of-the art TPS. Fig. 3 shows a practical example of the different steps in such dose redistribution planning. A prospective phase II study should naturally validate the clinical relevance of such dose redistribution concept limiting radiation-induced lung damage. 4DCT acquisition at baseline and during follow-up on calibrated machines will be crucial to eliminate uncertainties in terms of position (image registration) and density (breathing phases). Finally, radiomics studies defining features other than baseline density could enhance the predictive models [38].

\section{Conflicts of interest}

Nothing to disclose.

\section{Acknowledgement}

This project has received funding from the European Union's Seventh Framework Programme for research, technological development and demonstration under grant agreement no 601826 (REQUITE). 


\section{Appendix A. Supplementary data}

Supplementary data associated with this article can be found, in the online version, at http://dx.doi.org/10.1016/j.radonc.2016.11. 021.

\section{References}

[1] Kwa SLS, Lebesque JV, Theuws JC, et al. Radiation pneumonitis as a function of mean lung dose: an analysis of pooled data of 540 patients. Int J Radiat Biol Phys 1998;42:1-9.

[2] Seppenwoolde Y, Lebesque JV, De Jeager K, et al. Comparing different NTCP models that predict the incidence of radiation pneumonitis. Int J Radiat Biol Phys 2003;55:724-35.

[3] Rancati T, Ceresoli GL, Gagliardi G, Schipani S, Cattaneo GM. Factors predicting radiation pneumonitis in lung cancer patients: a retrospective study. Radiother Oncol 2003;67:275-83.

[4] Marks LB, Bentzen SM, Deasy JO, et al. Radiation dose-volume effects in the lung. Int J Radiat Biol Phys 2010:76:S70-6.

[5] De Ruysscher D, Faivre-Finn C, Nestle U, et al. European organisation for research and treatment of cancer recommendations for planning and delivery of high-dose, high-precision radiotherapy for lung cancer. J Clin Oncol 2010;28:5301-10.

[6] Vogelius IR, Bentzen SM. A literature-based meta-analysis of clinical risk factors for development of radiation induced pneumonitis. Acta Oncol 2012;51:975-83.

[7] Tucker SL, Li M, Xu T, et al. Incorporating single-nucleotide polymorphisms into the Lyman model to improve prediction of radiation pneumonitis. Int $\mathrm{J}$ Radiat Biol Phys 2013;85:251-7.

[8] De Ruysscher D, Sharifi H, Defraene G, et al. Quantification of radiationinduced lung damage with CT scans: the possible benefit for radiogenomics. Acta Oncol 2013:52:1405-10.

[9] Hoffmann EA, McLennan G. Assessment of the pulmonary structure-function relationship and clinical outcomes measures: quantitative volumetric CT of the lung. Acad Radiol 1997;4:758-76.

[10] Seppenwoolde Y, De Jaeger K, Boersma LJ, Belderbos JS, Lebesque JV. Regional differences in lung radiosensitivity after radiotherapy for non-small cell lung cancer. Int J Radiat Biol Phys 2004;60:748-58.

[11] Hope AJ, Lindsay PE, El Naqa I, et al. Modeling radiation pneumonitis risk with clinical, dosimetric and spatial parameters. Int J Radiat Biol Phys 2006;65:112-24.

[12] Kyas I, Hof H, Debus J, Schlegel W, Karger CP. Prediction of radiation-induced changes in the lung after stereotactic body radiation therapy for non-small cell lung cancer. Int J Radiat Biol Phys 2007;67:768-74.

[13] Lambin P, Petit SF, Aerts HJWL, et al. The ESTRO Breur Lecture 2009. From population to voxel-based radiotherapy: exploiting intra-tumour and intraorgan heterogeneity for advanced treatment of non-small cell lung cancer. Radiother Oncol 2010;96:145-52.

[14] Palma DA, van Sörnsen de Koste J, Verbakel W, Vincent A, Senan S. Lung density changes after stereotactic radiotherapy: a quantitative analysis in 50 patients. Int J Radiat Biol Phys 2011;81:974-8.

[15] Diot Q, Kavanagh B, Schefter T, Gaspar L, Stuhr K, Miften M. Regional normal lung tissue density changes in patients treated with stereotactic body radiation therapy for lung tumors. Int J Radiat Biol Phys 2012;84:1024-30.

[16] Bernchou U, Schytte T, Bertelsen A, Bentzen SM, Hansen O, Brink C. Time evolution of regional CT density changes in normal lung after IMRT for NSCLC. Radiother Oncol 2013;109:89-94.

[17] Diot Q, Marks L, Bentzen S, et al. Comparison of radiation-induced normal lung tissue density changes for patients from different institutions receiving conventional or hypofractionated treatments. Int J Radiat Biol Phys 2014:89:626-32.

[18] Defraene G, van Elmpt W, Crijns W, Slagmolen P, De Ruysscher D. CT characteristics allow identification of patient-specific susceptibility for radiation-induced lung damage. Radiother Oncol 2015;117:29-35.
[19] Ghobadi G, Wiegman EM, Langendijk JA, Widder J, Coppes RP, van Luijk P. A new CT-based method to quantify radiation-induced lung damage in patients. Radiother Oncol 2015;117:4-8.

[20] Moiseenko V, Craig T, Bezjak A, Van Dyk J. Dose-volume analysis of lung complications in the radiation treatment of malignant thymoma: a retrospective review. Radiother Oncol 2003;67:265-74.

[21] Kong F-M, Hayman JA, Griffith KA, et al. Final toxicity results of a radiationdose escalation study in patients with non-small cell lung cancer (NSCLC): predictors for radiation pneumonitis and fibrosis. Int J Radiat Biol Phys 2006;65:1075-86

[22] Jone B, Dale R, Deehan C, Hopkins K, Morgan D. The role of biologically effective dose (BED) in clinical oncology. Clin Oncol 2001;13:71-81.

[23] Bentzen SM, Saunders MI, Dische S. From CHART to CHARTWEL in non-small cell lung cancer: clinical radiobiological modeling of the expected change in outcome. Clin Oncol 2002;14:372-81.

[24] Kimura T, Doi Y, Nakashima T. Combined ventilation and perfusion imaging correlates with the dosimetric parameters of radiation pneumonitis in radiation therapy planning for lung cancer. Int J Radiat Biol Phys 2015:93:778-87.

[25] Siva S, Thomas R, Callahan J, et al. High-resolution pulmonary ventilation and perfusion PET/CT allows for functionally adapted intensity-modulated radiotherapy in lung cancer. Radiother Oncol 2015;115:157-62.

[26] Yamamoto T, Kabus S, von Berg J, Lorenz C, Keall PJ. Impact of fourdimensional computed tomography pulmonary ventilation imaging-based functional avoidance for lung cancer radiotherapy. Int J Radiat Biol Phys 2011;79:279-88.

[27] Kimura T, Nishibuchi I, Murakami Y, et al. Functional image-guided radiotherapy planning in respiratory-gated intensity-modulated radiotherapy for lung cancer patients with chronic obstructive pulmonary disease. Int J Radiat Biol Phys 2012;82:e663-70.

[28] Yamamoto T, Kabus S, Bal M, Keall P, Benedict S, Daly M. The first patient treatment of computed tomography ventilation functional image-guided radiotherapy for lung cancer. Radiother Oncol 2015;118:227-31.

[29] Farr KP, Kallehauge JF, Moller DS, et al. Inclusion of functional information from perfusion SPECT improves predictive value of dose-volume parameters in lung toxicity outcome after radiotherapy for non-small lung cancer: a prospective study. Radiother Oncol 2015;117:9-16.

[30] Mets OM, Buckens CF, Zanen P, et al. Identification of chronic obstructive pulmonary disease in lung cancer screening computed tomography scans. JAMA 2011:306:1775-81.

[31] Diciotti S, Sverzellati N, Kauczor H-U, et al. Defining the intra-subject variability of whole-lung CT densitometry in two lung cancer screening trials. Acad Radiol 2011;18:1403-11.

[32] Tuder RM, Yoshide T, Fijalkowka I, Biswal S, Petrache I. Role of lung maintenance program in the heterogeneity of lung destruction in emphysema. Proc Am Thorac Soc 2006;3:673-9.

[33] Bernchou U, Hansen O, Schytte T, et al. Prediction of lung density changes after radiotherapy by cone beam computed tomography response markers and pretreatment factors for non-small cell lung cancer patients. Radiother Oncol 2015;117:17-22.

[34] Cella L, D’Avino V, Palma G, et al. Modeling the risk of radiation-induced lung fibrosis: irradiated heart tissue is as important as irradiated lung. Radiother Oncol 2015;117:36-43.

[35] Nalbantov G, Kietselaer B, Vandecasteele K, et al. Cardiac comorbidity is an independent risk factor for radiation-induced lung toxicity in lung cancer patients. Radiother Oncol 2013;109:100-6.

[36] Bertelsen A, Schytte T, Bentzen SM, Hansen O, Nielsen M, Brink C. Radiation dose response of normal lung assessed by Cone Beam CT - a potential tool for biologically adaptive radiation therapy. Radiother Oncol 2011;100:351-5.

[37] Briere TM, Krafft S, Liao Z, Martel MK. Lung size and the risk of radiation pneumonitis. Int J Radiat Biol Phys 2016:94:377-84.

[38] Park YS, Seo JB, Kim N, et al. Texture-based quantification of pulmonary emphysema on high-resolution computed tomography: comparison with density-based quantification and correlation with pulmonary function. Invest Radiol 2008;43:395-402. 